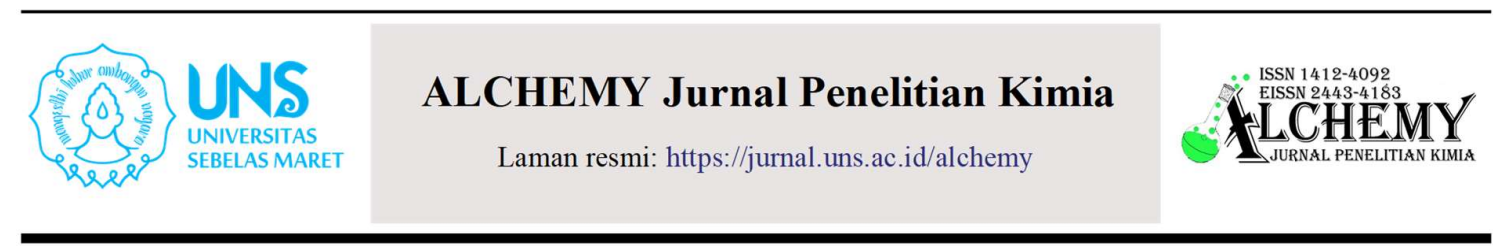

\title{
Produksi Bioetanol sebagai Energi Terbarukan dari Rumput Laut Ulva reticulata Asal
} Pulau Timor

\author{
Sefrinus Maria Dolfi Kolo*, Jefry Presson, Pricilia Amfotis \\ Program Studi Kimia, Universitas Timor, Jl. El Tari - Km. 09 Kota Kefamenanu, Timor Tengah Utara 85613 telp. (0388)2431111 \\ "Corresponding author: sefriunimor@gmail.com \\ DOI: 10.20961/alchemy.17.2.45476.159-167
}

Received 09 November 2020, Accepted 09 June 2021, Published 09 September 2021

Kata kunci:

bioetanol; delignifikasi; fermentasi;

hidrolisis; Ulva reticulata.

Keywords:

bioethanol; delignification; fermentation; hydrolysis; Ulva reticulata.

\begin{abstract}
ABSTRAK. Rumput laut dengan kandungan karbohidrat dan lipid yang tinggi dianggap menjadi sumber energi terbarukan generasi ketiga. Penelitian ini bertujuan menentukan kadar gula pereduksi optimum, mengetahui tekstur permukaan serbuk sebelum dan sesudah hidrolisis serta menentukan kadar etanol hasil fermentasi. Kandungan karbohidrat rumput laut Ulva reticulata dapat dikonversi menjadi gula heksosa dan pentosa (glukosa, arabinosa, ramnosa, dan xilosa) melalui hidrolisis asam. Campuran gula optimum hasil proses hidrolisis kemudian dikonversi menjadi etanol menggunakan ragi Saccharomyces cerevisiae. Fermentasi dilakukan dengan konsentrasi inokulum $10 \%$ (v/v) selama 5 hari pada temperatur $30^{\circ} \mathrm{C}$ dan pH 4,5. Analisis tekstur permukaan sampel dilakukan dengan Scanning Electron Microscopy (SEM). Analisis gula pereduksi dilakukan dengan metode DNS (Dinitro salisilat). Analisis etanol dilakukan dengan uji kualitatif dan kuantitatif menggunakan metode berat jenis dan kromatografi gas. Hasil penelitian menunjukkan bahwa kadar gula pereduksi meningkat seiring meningkatnya suhu hidrolisis pada suhu $75{ }^{\circ} \mathrm{C}$ ke $150{ }^{\circ} \mathrm{C}(2,3-23,7 \mathrm{~g} / \mathrm{L})$ dan mengalami penurunan kadar pada suhu $175{ }^{\circ} \mathrm{C}$ menjadi $17,1 \mathrm{~g} / \mathrm{L}$. Hasil analisis dengan variasi konsentrasi terhadap waktu 30, 40, 50, dan 60 menit terlihat bahwa kadar gula pereduksi meningkat seiring meningkatnya waktu hidrolisis dari 30 menit sampai 50 menit yakni 23,7 $33,4 \mathrm{~g} / \mathrm{L}$ dan mengalami penurunan pada waktu 60 menit yakni 19,2 g/L. Kadar gula pereduksi optimum sebesar $33,4 \mathrm{~g} / \mathrm{L}$ pada suhu $150{ }^{\circ} \mathrm{C}$ dengan konsentrasi asam $2 \%$ pada waktu hidrolisis 50 menit. Tekstur permukaan serbuk sebelum dan sesudah hidrolisis mengalami perubahan yang signifikan. Hasil uji kualitatif etanol hasil fermentasi dibuktikan dengan adanya perubahan warna dari jingga menjadi biru. Hasil uji kadar etanol dengan metode berat jenis yakni sebesar $1 \%$ dan metode kromatografi gas sebesar $5,02 \%$.
\end{abstract}

\begin{abstract}
Bioethanol Production as Renewable Energy from Ulva Reticulata Seaweed from Timor Island. Seaweed with carbohydrate and lipid content is considered to be the third generation of renewable energy sources. The carbohydrate content of Ulva reticulata seaweed can be converted into hexose and pentose sugars (glucose, arabinose, ramnose, and xylose) through acid hydrolysis. The optimum sugar mixture resulting from the hydrolysis process is then converted to ethanol using Saccharomyces cerevisiae yeast. Fermentation was carried out with an inoculum concentration of $10 \%$ $(\mathrm{v} / \mathrm{v})$ for five days at a temperature of $30^{\circ} \mathrm{C}$ and a $\mathrm{pH}$ of 4.5 . Analysis of the surface texture of the sample was carried out by Scanning Electron Microscopy (SEM). Reducing sugar analysis was performed using the DNS (Dinitrosalicylate) method. Ethanol analysis was carried out by qualitative and quantitative tests using specific gravity and gas chromatography methods. The results showed that the reducing sugar content increased with increasing hydrolysis temperature at $75^{\circ} \mathrm{C}$ to $150{ }^{\circ} \mathrm{C}(2.3-23.7 \mathrm{~g} / \mathrm{L})$ and decreased levels at $175{ }^{\circ} \mathrm{C}$ to $17.1 \mathrm{~g} / \mathrm{L}$. The results of the analysis with various concentrations of $30,40,50$, and 60 minutes showed that reducing sugar levels increased with increasing hydrolysis time from 30 minutes to 50 minutes, namely $23.7-33.4 \mathrm{~g} / \mathrm{L}$ and decreased at 60 minutes, namely $19.2 \mathrm{~g} / \mathrm{L}$. The optimum reducing sugar content was $33.4 \mathrm{~g} / \mathrm{L}$ at $150{ }^{\circ} \mathrm{C}$ with an acid concentration of $2 \%$ at 50 minutes of hydrolysis. Powder surface texture before and after hydrolysis experienced significant changes. The qualitative test results of fermented ethanol are evidenced by a change in color from orange to blue. The results of the ethanol content test using the specific gravity method were $1 \%$, and that using the gas chromatography method was $5.02 \%$.
\end{abstract}

\section{PENDAHULUAN}

Kendala yang dihadapi dalam mengembangkan produksi bioetanol di Indonesia yakni bahan baku yang terbatas, persoalan ketersediaan lahan, dan efisiensi biaya produksi (Murdiyatmo, 2006). Salah satu sumber bahan baku potensial untuk dijadikan bahan baku bioetanol yakni makroalga. Dibandingkan dengan biomassa lain seperti jagung dan tebu, produktivitas makroalga lebih besar 5 kali lipat. Untuk menggantikan 60 miliar gallon bahan bakar fosil, hanya dibutuhkan makroalga sekitar kurang dari 3\% perairan pesisir dunia (Adini et al., 
2014). Sumber bioetanol (jagung, tebu, dan gandum) masih berkompetisi dengan sektor pangan dan pakan, selain itu memerlukan area tanah yang cukup luas (Jalilnejad and Ghasemzadeh, 2019). Tujuh puluh persen (70\%) permukaan bumi ditutupi oleh laut yang hidup berbagai mikroalga dan rumput laut yang dapat dikonversi menjadi bioetanol (Suutari et al., 2015).

Telah diketahui bahwa Ulva reticulata mengandung karbohidrat berupa heteropolisakarida jenis glukosa, arabinosa, ramnosa, dan xilosa yang sangat berlimpah (Yu-Qing et al., 2016). Rumput laut dengan kandungan karbohidrat dan lipid dianggap menjadi sumber energi terbarukan generasi ke-3 (Mathimani and Pugazhendhi, 2019). Tentu hal ini sangat mendukung program Pemerintah Indonesia untuk mewujudkan pemanfaatan energi terbarukan sekurang-kurangnya 23\% pada tahun 2025 (Rochman, 2015). Selain itu, rumput laut ini banyak tersebar di laut Timor, Nusa Tenggara Timur. Namun, Ulva reticulata ini belum dimanfaatkan oleh masyarakat di Pulau Timor sehingga menjadi sampah yang mengurangi estetika pantai. Di sisi lain, rumput laut ini bukan merupakan bahan makanan, sehingga tidak berkompetisi dengan pangan saat menjadi bioetanol.

Sintesis bioetanol dari rumput laut dapat dilakukan melalui proses hidrolisis dan dilanjutkan dengan proses fermentasi (Park et al., 2012). Proses hidrolisis menggunakan asam seperti $\mathrm{H}_{2} \mathrm{SO}_{4}$ memberikan rendemen bioetanol yang lebih tinggi dibandingkan enzim (Adini et al., 2014). Salah satu kendala dalam produksi bioetanol yakni pada perlakuan awal (pretreatment). Proses delignifikasi yang berlangsung dalam waktu lama dapat menyebabkan konversi komponen lignoselulosa menjadi senyawa sekunder seperti xylitol, asam suksinat, asam laktat, furfural, hidroksimetilfurfural, asam asetat, dan gliserol, yang bertindak sebagai penghambat dalam fase hidrolisis berikutnya. Pada penelitian ini, perlakuan awal (deliginifikasi dan hidrolisis) menggunakan microwave irradiation sebagai salah satu alternatif dalam meningkatkan efisiensi dalam reaksi kimia dan memiliki banyak keuntungan, yaitu waktu yang dibutuhkan relatif lebih singkat dibandingkan dengan metode konvensional, laju reaksi hidrolisis pati menjadi glukosa meningkat 50 - 100 kali menggunakan microwave irradiation, waktu produksinya lebih pendek, menghemat biaya, selain itu lebih ramah lingkungan karena konsentrasi asam yang digunakan lebih rendah (Kolo et al., 2020).

Hidrolisis rumput laut dengan $\mathrm{H}_{2} \mathrm{SO}_{4}$ pada konsentrasi $9 \%$ berat selama 70 menit dapat memaksimalkan gula pereduksi (Alfonsín et al., 2019). Fermentasi menggunakan Saccharomyces cerevisiae pada kondisi konsentrasi inokulum 17,5 mg/mL (59\%) selama 4 jam dapat memberikan rendemen bioetanol sebesar 55,9\% (Tan and Lee, 2014). Yu et al., 2020 melaporkan bahwa Mikroalga Chlorella vulgaris dapat dihidrolisis dengan asam menggunakan microwave irradiation yang menghasilkan gula pereduksi sebesar $98,11 \mathrm{~g} / \mathrm{L}$ dan etanol sebesar $7,61 \%$.

Sejauh pengetahuan penulis, penelitian mengenai produksi bioetanol dari Ulva reticulata belum pernah dilakukan. Oleh karena itu, perlu dilakukan penelitian untuk menyelidiki setiap tahapan produksi bioetanol dari Ulva reticulata. Pada penelitian ini, rumput laut asal laut Timor ini dikonversi menjadi bioetanol melalui tahap hidrolisis dengan $\mathrm{H}_{2} \mathrm{SO}_{4}$ encer dilanjutkan dengan tahap fermentasi. Penelitian ini menggunakan variabel suhu dan waktu dengan dua metode yang berbeda yakni deliginifikasi dan hidrolisis untuk mencari keadaan optimum bagi kedua tahapan tersebut. Tekstur karbohidrat sebelum dan sesudah hidrolisis dianalisis dengan SEM. Keberhasilan hidrolisis pada penelitian ini diselidiki dengan analisis gula pereduksi. Bioetanol yang diproduksi kemudian dikarakterisasi dengan metode berat jenis (piknometer) dan kromatografi gas (GC).

\section{METODE PENELITIAN}

Sampel Ulva reticulata yang digunakan dalam penelitian ini didapatkan dari pesisir pantai pasir panjang, Kecamatan Kelapa Lima, Kota Kupang. Pelarut yang digunakan pada tahap Pretreatment yakni $\mathrm{H}_{2} \mathrm{SO}_{4}(\mathrm{Merck})$ dan $\mathrm{NaOH}$ (teknis), bahan penetralan media fermentasi yaitu $\mathrm{HCl}$ (teknis), bahan untuk tahap analisa yaitu: glukosa (Merck), $\mathrm{H}_{2} \mathrm{SO}_{4}$ (Merck), etanol (Merck), asam asetat (Merck). Media agar miring yaitu: (ragi ekstrak $10 \mathrm{~g} / \mathrm{L}$; pepton $20 \mathrm{~g} / \mathrm{L}$; glukosa $20 \mathrm{~g} / \mathrm{L}$; agar $25 \mathrm{~g} / \mathrm{L}$ ), media inokulum terdiri atas media inokulum Saccaromyces cerevisiae (yeast ekstrak $5 \mathrm{~g} / \mathrm{L}$; pepton $5 \mathrm{~g} / \mathrm{L}$; xilosa dan glukosa $20 \mathrm{~g} / \mathrm{L}$ sebagai sumber karbon), media fermentasi terdiri atas ekstrak ragi $5 \mathrm{~g} / \mathrm{L}$; pepton $5 \mathrm{~g} / \mathrm{L}$; $\mathrm{KH}_{2} \mathrm{PO}_{4} 5 \mathrm{~g} / \mathrm{L}, \mathrm{MgSO}_{4} .7 \mathrm{H}_{2} \mathrm{O} 0,4 \mathrm{~g} / \mathrm{L}, \mathrm{NH}_{4} \mathrm{SO}_{4} 0,5 \mathrm{~g} / \mathrm{L}$; hidrolisat glukosa.

Penimbangan dilakukan menggunakan neraca analitik (Mettler Toledo AG 204, USA). Pengecekan pH menggunakan $\mathrm{pH}$ meter (Thermo Orion model $710 \mathrm{~A}+$ ). Alat dan media pertumbuhan disterilisasi dengan autoclave (Sturdy SA-232 X). Inkubasi dilakukan menggunakan inkubator temperatur $37{ }^{\circ} \mathrm{C}$ (FISHER model 503), dan water bath (Precision 280 series), kromatografi gas (GC), spektrofotometer UV-Vis, fermentor, dan Scanning Electron Microscope (SEM). 


\section{Preparasi dan Delignifikasi Rumput Laut Ulva reticulata}

Preparasi Ulva reticulata terdiri dari dua langkah yaitu pengeringan di bawah sinar matahari dan penggilingan menggunakan blender, kemudian disaring menggunakan ayakan 100 mesh sehingga diperoleh serbuk Ulva reticulata. Serbuk dianalisis morfologinya menggunakan SEM. Metode delignifikasi dikembangkan dari penelitian (Kolo et al., 2020). Sebanyak 20 gram serbuk ukuran 100 mesh disuspensi dengan $300 \mathrm{~mL} \mathrm{NaOH}$ $2 \%$ lalu dipanaskan menggunakan reaktor microwave pada temperatur $90{ }^{\circ} \mathrm{C}$ selama 30 menit. Hasil pemanasan selanjutnya disaring dan dicuci dengan air panas sampai netral. Serbuk hasil delignifikasi dikeringkan dan dihidrolisis dengan asam.

\section{Hidrolisis Tepung Rumput Laut Ulva reticulata}

Tahapan hidrolisis pada tepung Ulva reticulata bertujuan untuk menghidrolisis selulosa menjadi bentuk monosakarida seperti glukosa. Hidrolisis dilakukan dengan variasi suhu dan waktu menggunakan dua metode yakni hidrolisis dengan delignifikasi dan hidrolisis tanpa delignifikasi seperti tertera pada Tabel 1.

Tabel 1. Optimasi hidrolisis serbuk Ulva reticulata dengan katalis asam.

\begin{tabular}{lcccc}
\hline \multirow{2}{*}{ Perlakuan } & \multicolumn{2}{c}{ Delignifikasi + Hidrolisis } & Hidrolisis \\
\cline { 2 - 5 } & Waktu (menit) & Temperatur $\left({ }^{\circ} \mathbf{C}\right)$ & $\begin{array}{c}\text { Waktu } \\
\text { (menit) }\end{array}$ & Suhu ( $\left.{ }^{\circ} \mathbf{C}\right)$ \\
\hline 1 & 30 & $75,100,150,175,200$ & 30 & $75,100,150,175,200$ \\
2 & $30,40,50,60$ & Suhu optimum perlakuan 1 & $30,40,50,60$ & Suhu optimum perlakuan 1 \\
\hline
\end{tabular}

Hidrolisis asam dilakukan dengan cara sebagai berikut: $3 \mathrm{~g}$ tepung tepung Ulva reticulata dan $100 \mathrm{~mL}$ $\mathrm{H}_{2} \mathrm{SO}_{4} 2 \%(\mathrm{v} / \mathrm{v})$ dimasukkan ke dalam erlenmeyer $250 \mathrm{~mL}$, kemudian dipanaskan menggunakan microwave. Hasil hidrolisis tersebut selanjutnya didinginkan pada suhu ruang dan disaring lalu dinetralkan untuk proses selanjutnya. Fraksi padat dilihat tekstur permukaannya dengan alat SEM, sedangkan fraksi cair dianalisis kandungan gula pereduksi dengan metode DNS menggunakan spektrofotometer UV-Vis (Susmiati, 2011).

\section{Fermentasi Hidrolisat Ulva reticulata}

Metode fermentasi dikembangkan dari penelitian Yadav et al. (2011). Fermentasi dilakukan dengan menggunakan ragi Sacharomyces cerevisiae. Volume kerja fermentasi untuk medium hidrolisat sebanyak 200 $\mathrm{mL}$. Hidrolisat serbuk Ulva reticulata sp terlebih dahulu dinetralkan untuk analisa gula pereduksi, lalu dimasukkan media fermentasi dan diautoklaf pada temperatur $121{ }^{\circ} \mathrm{C}$ selama 15 menit. Fermentasi dilakukan secara anaerobik selama 6 hari. Medium fermentasi menggunakan aquades sebagai pelarut. Fermentasi diatur pada $\mathrm{pH} 4,5$ dan temperatur $30{ }^{\circ} \mathrm{C}$ menggunakan $\mathrm{NaOH}$ atau $\mathrm{HCl} 2 \mathrm{M}$. Media inokulum $10 \%(\mathrm{v} / \mathrm{v}$ ) dimasukkan ke dalam medium fermentasi.

\section{Pemurnian (Distilasi) Bioetanol}

Hasil fermentasi selama 5 hari disaring menggunakan kertas saring, filtratnya dimasukkan ke dalam labu distilasi dan dipasangkan dengan rangkaian alat distilasi yang telah dirancang. Proses distilasi dilakukan pada suhu $75{ }^{\circ} \mathrm{C}$ sampai $80{ }^{\circ} \mathrm{C}$. Distilasi dilakukan selama 1 sampai 2 jam hingga etanol tidak menetes lagi. Distilat yang dihasilkan disimpan dalam wadah yang tertutup rapat (Windarti et al., 2014).

\section{Analisis Kualitatif Etanol Ulva reticulata}

Uji kualitatif etanol pada sampel hasil destilasi makroalga Ulva retculata dilakukan dengan cara oksidasi Kalium dikromat $\left(\mathrm{K}_{2} \mathrm{Cr}_{2} \mathrm{O}_{7}\right)$. Tabung reaksi dimasukkan $2 \mathrm{~mL} \mathrm{~K}_{2} \mathrm{Cr}_{2} \mathrm{O}_{7} \%$, 5 tetes $\mathrm{H}_{2} \mathrm{SO}_{4}$ pekat dan $1 \mathrm{~mL}$ sampel. Sampel positif mengandung etanol ditandai dengan perubahan warna dari jingga menjadi hijau (Bahroni and Istianah, 2017).

\section{Analisis Kuantitatif Kadar Etanol dengan Metode Piknometer dan Kromatografi Gas (GC)}

Piknometer yang digunakan berukuran $5 \mathrm{~mL}$ dan menggunakan timbangan neraca analitik yang dikembangkan dari Windarti et al. (2014) dengan prosedur yang pertama menimbang berat piknometer kosong diperoleh berat (a) g, yang kedua menimbang berat piknometer yang telah terisi penuh akuades diperoleh berat (b) g, setelah mendapatkan nilai a dan b dihitung volume piknometer dengan rumus pada persamaan 1 . 


$$
\text { Volume }=\frac{\mathrm{b}-\mathrm{a}}{0,996797}=\mathrm{c} \mathrm{mL}
$$

Prosedur yang ketiga menimbang berat piknometer yang telah terisi penuh distilat bioetanol diperoleh berat (d) g setelah didapatkan volume piknometer (c) g. Selanjutnya dihitung densitasnya menggunakan rumus pada persamaan 2 .

$$
\text { Densitas }=\frac{\mathrm{d}-\mathrm{a}}{\mathrm{c}}=\frac{\text { berat pikno sampel-berat pikno kosong }}{\text { volume piknometer }}
$$

Untuk melihat kadar bioetanol yang dihasilkan lebih akurat, maka dilakukan analisa menggunakan Gas Chromatography (GC) Agilent 7890a.

\section{HASIL DAN PEMBAHASAN}

\section{Analisis Tekstur Permukaan Menggunakan Scanning Electron Microscope (SEM)}

Tujuan penggilingan dan pengayakan Ulva reticulata menjadi serbuk yakni untuk memperluas permukaan bahan atau sampel sehingga memudahkan saat proses hidrolisis menggunakan asam encer $\left(\mathrm{H}_{2} \mathrm{SO}_{4} \% \mathrm{v} / \mathrm{v}\right)$. Hasil perlakuan awal pada serbuk Ulva reticulata selanjutnya dianalisis secara kualitatif dan kuantitatif. Secara kualitatif, dilakukan dengan pengamatan SEM untuk tiap tahap perlakuan awal sedangkan analisis kuantitatif dilakukan dengan metode DNS. Pengujian SEM bertujuan untuk melihat permukaan serbuk sebelum dan setelah perlakuan awal. Pengujian dilakukan pada 2 sampel yaitu serbuk awal ukuran 100 mesh, serbuk setelah delignifikasi dan serbuk hasil hidrolisis dengan perbesaran $800 \times($ Gambar 1).
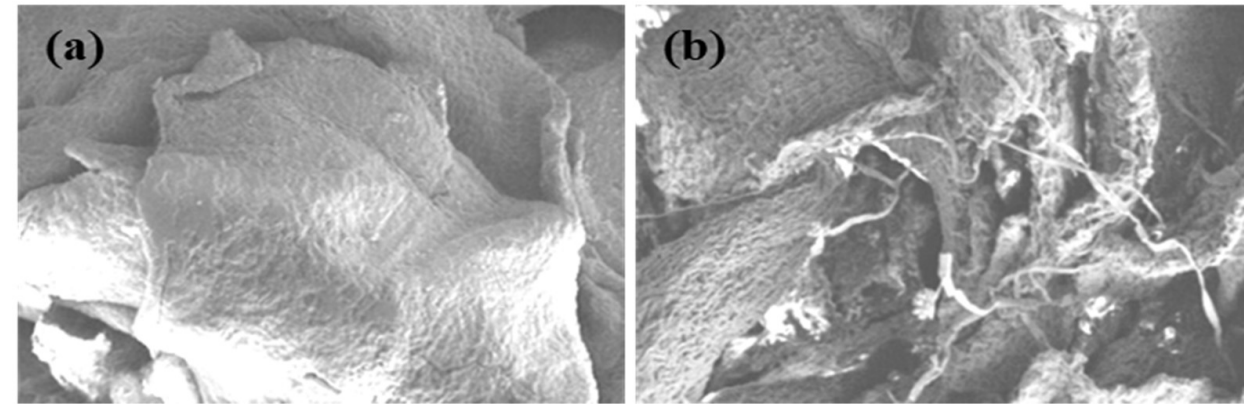

Gambar 1. Citra SEM morfologi permukaan Ulva reticulata (a) tanpa perlakuan awal dan (b) setelah hidrolisis.

Berdasarkan analisis Scanning Electron Microscope (SEM) pada hasil perlakuan awal serbuk menunjukkan bahwa ada pengaruh atau perubahan tekstur permukaan setelah mendapat perlakuan gelombang mikro. Sebelum delignifikasi dan hidrolisis, tekstur permukaan serbuk masih kompak dan utuh (Gambar 1a). Sedangkan setelah didelignifikasi dengan $\mathrm{NaOH}$ dan dihidrolisis dengan $\mathrm{H}_{2} \mathrm{SO}_{4}$ terlihat bahwa tekstur permukaan serbuk mengalami kerusakan yang signifikan (Gambar 1b). Delignifikasi menggunakan $\mathrm{NaOH}$ dapat merusak atau melepaskan struktur lignin yang membungkus selulosa dan hemiselulosa pada bahan lignoselulosa. Adapun proses hidrolisis menggunakan asam $\left(\mathrm{H}_{2} \mathrm{SO}_{4}\right)$ dapat dilakukan apabila struktur selulosa dan hemiselulosa sudah terekspos. Hidrolisis dengan asam akan memutuskan ikatan $\beta$-1,4-glikosidik pada selulosa dan memutuskan $\beta$ 1,4-D-piranosil pada hemiselulosa menjadi gula sederhana (glukosa, xilosa, galaktosa, arabinosa, dan manosa) (Wang et al., 2013).

\section{Hidrolisis Ulva reticulata dengan Microwave Variasi Suhu Hidrolisis Menggunakan Microwave}

Proses perlakuan awal dilakukkan dengan 2 metode yakni hidrolisis tanpa delignifikasi dan hidrolisis dengan delignifikasi. Kadar gula pereduksi bertambah seiring meningkatnya suhu hidrolisis pada suhu $75{ }^{\circ} \mathrm{C}$ ke $150{ }^{\circ} \mathrm{C}$ yaitu sebesar 2,3 sampai $23,7 \mathrm{~g} / \mathrm{L}$ untuk hidrolisis tanpa delignifikasi dan 5,8 sampai $27,3 \mathrm{~g} / \mathrm{L}$ untuk hidrolisis dengan delignifikasi (Gambar 2). Penurunan kadar terjadi pada suhu $175^{\circ} \mathrm{C}$ menjadi $17,1 \mathrm{~g} / \mathrm{L}$ dan 24,3 $\mathrm{g} / \mathrm{L}$. Hal ini disebabkan karena pemanasan yang terlalu tinggi mengakibatkan gula mengalami proses karamelisasi yang ditunjukkan dengan warna hidrolisat yang semakin pekat setelah pemanasan. Hasil analisis DNS (Dinitrosalisilat) menunjukkan bahwa kadar gula pereduksi tertinggi pada suhu $150{ }^{\circ} \mathrm{C}$ yakni $23,7 \mathrm{~g} / \mathrm{L}$ untuk hidrolisis tanpa delignifikasi dan $27,3 \mathrm{~g} / \mathrm{L}$ ketika proses hidrolisis dilakukan selama 30 menit. Suhu 
optimum yang menghasilkan kadar gula pereduksi optimal tersebut kemudian digunakan untuk optimasi waktu hidrolisis.

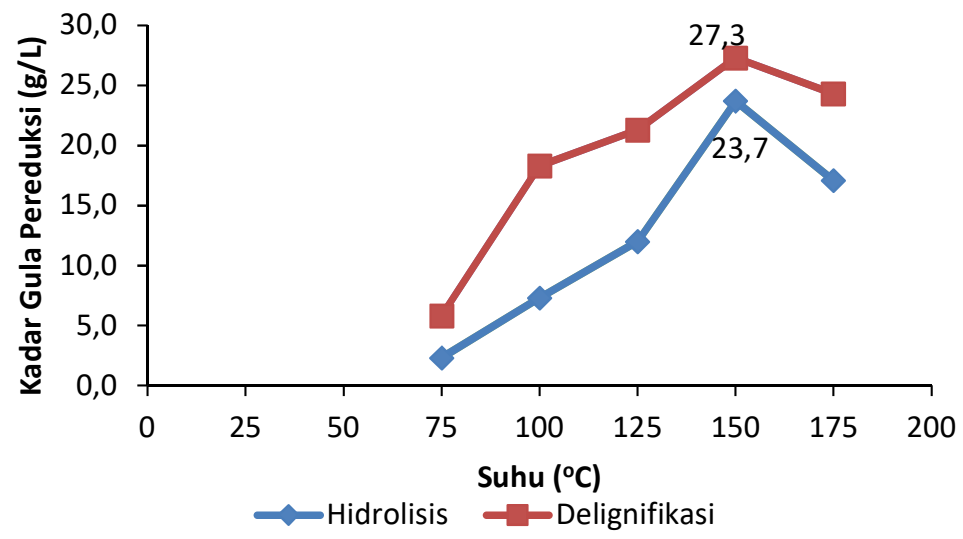

Gambar 2. Perbandingan deliginifikasi dan hidrolisis dengan variasi suhu terhadap kadar gula pereduksi.

Pengaruh waktu hidrolisis terhadap kadar gula pereduksi disajikan pada Gambar 3. Hasil penelitian menunjukkan bahwa kadar gula pereduksi meningkat seiring bertambahnya waktu hidrolisis dari 30 menit ke 50 menit (23,7 sampai 33,4 g/L untuk hidrolisis tanpa delignifikasi) dan mengalami penurunan kadar gula pada waktu 60 menit menjadi 19,2 g/L. Hidrolisis dengan delignifikasi mengalami peningkatan kadar gula sebesar $16,4-28 \mathrm{~g} / \mathrm{L}$. Hasil analisis DNS (Dinitrosalisilat) menunjukkan bahwa kadar gula pereduksi tertinggi pada waktu 50 menit yakni 33,4 g/L untuk hidrolisis tanpa delignifikasi dan $28 \mathrm{~g} / \mathrm{L}$ ketika proses hidrolisis dilakukan dengan delignifikasi selama 60 menit. Proses hidrolisis menggunakan asam sulfat dengan konsentrasi yang rendah akan menghasilkan rendemen glukosa hingga 50\% dalam waktu yang cukup singkat (Xiang et al., 2003). Waktu optimum yang menghasilkan kadar gula pereduksi optimal tersebut kemudian dipakai untuk produksi dan dilanjutkan proses fermentasi.

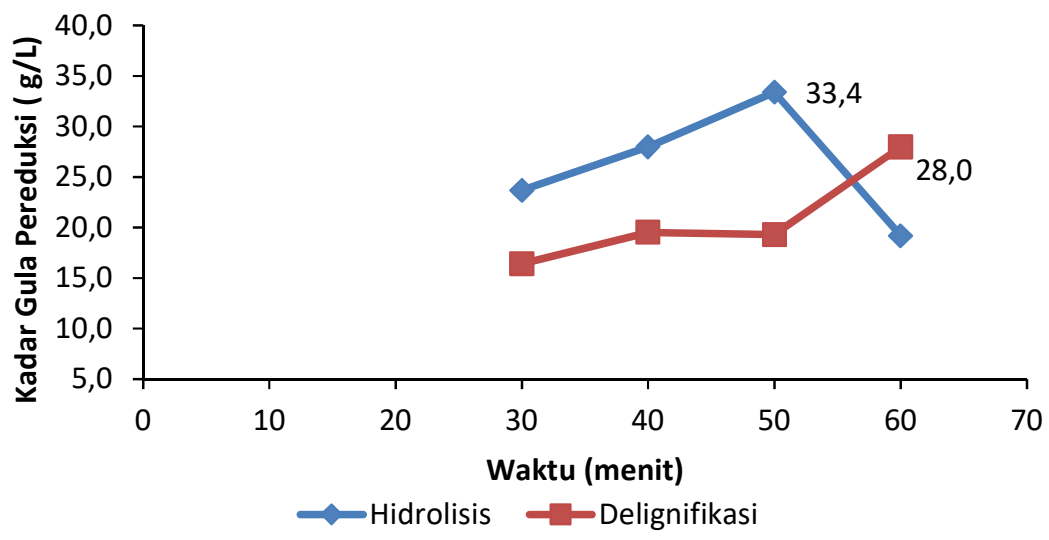

Gambar 3. Perbandingan deliginifikasi dan hidrolisis dengan variasi waktu terhadap kadar gula pereduksi.

Menurut Xiang et al. (2003), proton dari asam akan berinteraksi secara cepat dengan ikatan glikosidik oksigen pada dua unit gula sehingga akan membentuk asam konjugasi. Keberadaan asam konjugasi menyebabkan konformasi tidak stabil sehingga terjadi pemutusan ikatan $\mathrm{C}-\mathrm{O}$ dan membebaskan asam konjugasi pada konformasi yang tidak stabil. Keberadaan air pada sistem akan menyebabkan $\mathrm{OH}^{-}$dari air berikatan dengan ion karbonium sehingga membebaskan gula dan proton. Proton yang terbentuk akan berinteraksi secara cepat dengan ikatan glikosidik oksigen pada dua unit gula yang lain. Proses tersebut terjadi secara kontinyu sampai semua molekul selulosa terhidrolisis menjadi glukosa. Penurunan kadar gula saat suhu mencapai $175{ }^{\circ} \mathrm{C}$ disebabkan karena pemanasan yang terlalu tinggi mengakibatkan gula mengalami proses karamelisasi yang ditunjukkan dengan warna hidrolisat yang semakin pekat setelah pemanasan. 
Hidrolisis menggunakan microwave irradiation merupakan sebuah metode baru dalam bidang energi terbarukan yang memiliki keunggulan dibandingkan metode konvensional. Pemanasan yang merata dapat meningkatkan hasil gula pereduksi pada proses hidrolisis menggunakan asam encer. Penelitian Teh et al. (2017) dengan melakukan hidrolisis Euchema denticulactum menggunakan microwave dapat meningkatkan hasil gula pereduksi sebesar 51,47 g/L sedangkan Yu et al., (2020) menghasilkan gula pereduksi optimum sebesar 98,11 $\mathrm{g} / \mathrm{L}$ dengan hidrolisis menggunakan microwave irradiation. Berdasarkan kedua penelitian tersebut dapat disimpulkan bahwa hidrolisis menggunakan microwave irradiation dapat mempengaruhi kadar gula pereduksi.

Nikolić et al. (2010) melaporkan bahwa rendahnya rendemen glukosa disebabkan oleh adanya degradasi gula hasil hidrolisis yang terbentuk karena temperatur reaksi yang digunakan sangat tinggi. Temperatur yang dibutuhkan adalah mencapai $200{ }^{\circ} \mathrm{C}$. Degradasi gula tersebut tidak hanya menurunkan konversi reaksi, namun juga dapat meracuni mikroorganisme pada saat reaksi fermentasi pada pembentukan etanol. Oleh karena itu, dalam penelitian ini perlakuan awal dilakukan menggunakan pemanasan dengan bantuan microwave. Pemanasan dengan bantuan iradiasi microwave dapat digunakan secara langsung dalam reaksi hidrolisis asam encer untuk konversi biomassa berpati menjadi etanol. Rendahnya waktu kontak dan konsumsi energi pada saat operasi reaksi microwave, akan menurunkan pembentukan produk sekunder yang tidak diinginkan. Pemanasan dengan microwave dapat mengkonversi langsung pati menjadi gula dalam waktu yang relatif rendah. Dibandingkan dengan pemanasan konvensional, laju reaksi hidrolisis pati menjadi glukosa meningkat 100 kali dengan penggunaan iradiasi microwave.

\section{Fermentasi Hidrolisat Ulva reticulata}

Langkah terakhir dari penelitian ini yakni fermentasi hidrolisat Ulva reticulata agar glukosa dikonversi menjadi etanol menggunakan ragi Saccaromyces cereviceae. Berdasarkan hasil fermentasi diduga ada kandungan etanol sehingga dilanjutkan dengan tahap pemurnian melalui distilasi sehingga mendapatkan etanol murni.

\section{Analisis Kualitatif Etanol Ulva reticulata}

Uji kualitatif bioetanol dilakukan dengan metode oksidasi dengan Kalium dikromat $\left(\mathrm{K}_{2} \mathrm{Cr}_{2} \mathrm{O}_{7}\right)$. Hasil positif jika terjadi perubahan dari warna jingga menjadi hijau kebiruan (Tabel 4). Hal ini menunjukkan adanya etanol yang dihasilkan selama proses fermentasi. Reaksi oksidasi yang terjadi ditunjukkan pada persamaan 3 .

$$
\mathrm{CH}_{3} \mathrm{CH}_{2} \mathrm{OH}+2 \mathrm{~K}_{2} \mathrm{Cr}_{2} \mathrm{O}_{7}+8 \mathrm{H}_{2} \mathrm{SO}_{4} \rightarrow 3 \mathrm{CH}_{3} \mathrm{COOH}+2 \mathrm{Cr}\left(\mathrm{SO}_{4}\right)_{3}+2 \mathrm{~K}_{2} \mathrm{SO}_{4}+11 \mathrm{H}_{2} \mathrm{O}
$$

Tabel 4. Hasil uji bioetanol.

\begin{tabular}{lll}
\hline Sampel & Hasil uji & Gambar \\
\hline Etanol Murni & Positif $(+)$ & $\rightarrow$ \\
$\begin{array}{l}\text { Bioetanol Makroalga Ulva } \\
\text { reticulata }\end{array}$ & Positif $(+)$ & \\
\hline
\end{tabular}

Etanol merupakan senyawa alkohol primer dimana pada atom $\mathrm{C}$ yang berikatan dengan gugus $\mathrm{OH}$ mengikat 2 atom $\mathrm{H}$, sehingga $\mathrm{K}_{2} \mathrm{Cr}_{2} \mathrm{O}_{7}$ akan mengoksidasinya menjadi asam astetat dalam waktu relatif singkat sehingga terjadi perubahan warna pada $\mathrm{K}_{2} \mathrm{Cr}_{2} \mathrm{O}_{7} 2 \%$ dari jingga ke hijau ketika etanol diteteskan. Warna hijau tersebut berasal dari $\mathrm{Cr}^{3+}$ dimana disebabkan karena turunnya biloks $\mathrm{Cr}^{6+}$ menjadi $\mathrm{Cr}^{3+} . \mathrm{H}_{2} \mathrm{SO}_{4}$ berfungsi sebagai katalis untuk mempercepat reaksi tersebut (Ansika, 2014).

\section{Analisis Kuantitatif Kadar Etanol dengan Metode Piknometer dan Kromatografi Gas (GC)}

Hasil pengukuran dengan pikometer diperoleh densitas Ulva reticulata sebesar 0,9927; masih lebih tinggi dibandingkan densitas etanol absolut yaitu sebesar 0,789. Etanol yang dihasilkan belum murni karena bercampur 
dengan air. Hal ini disebabkan oleh tidak dilakukan distilasi secara berulang dan kurang teliti dalam menjaga kestabilan temperatur sehingga uap yang keluar tidak hanya bioetanol melainkan bercampur dengan air. Berdasarkan konversi berat jenis maka etanol yang diperoleh adalah sebesar 1\%. Kadar etanol ini lebih tinggi dibandingkan penelitian terdahulu dengan metode microwave irradiation pada mikroalga Chorella SP GD oleh Yu et al. (2020) yang hanya mendapatkan kadar bioetanol sebesar $0,68 \%$.

Hasil analisis kadar etanol menggunakan kromatografi gas (GC) menunjukkan hasil distilasi bioetanol Ulva reticulata memiliki kemurnian sebesar 5,02\% yang terdeteksi pada waktu retensi 3,264 menit (Gambar 4). Hasil ini lebih tinggi jika dibandingkan penelitian terdahulu oleh Novia et al. (2017) yang memproduksi bioetanol dari sekam padi sebesar 1\%. Hasil pengukuran kadar etanol makroalga Ulva reticulata menggunakan GC lebih tinggi dibandingkan piknometer. Hal ini dapat terjadi karena berbagai faktor yakni jarak waktu antara analisa piknometer dengan analisa GC cukup lama (Windarti et al., 2014). Pengukuran kadar etanol menggunakan piknometer yang digunakan adalah densitas campuran etanol dan air, sedangkan pada GC hanya etanol yang dideteksi untuk diukur kadar etanolnya (Novia et al., 2017). Tingkat ketelitian alat piknometer dan GC yang berbeda. Kurangnya ketelitian saat mengukur berat jenis menggunakan piknometer sehingga terdapat udara yang masuk yang akan mempengaruhi hasil pada neraca analitik. (Windarti et al., 2014).

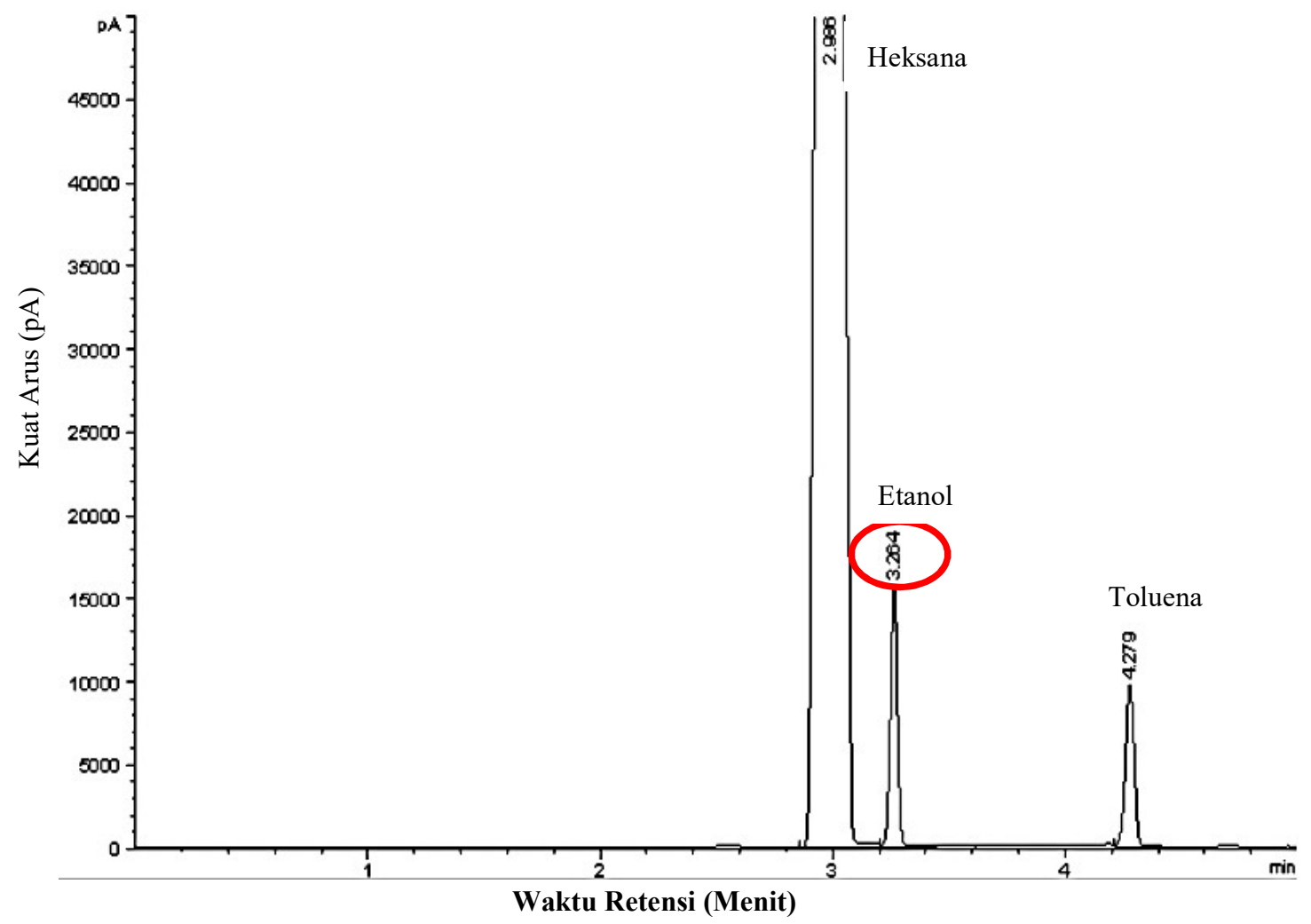

Gambar 4. Profil kromatogram sampel bioetanol.

Kromatogram sampel makroalga Ulva reticulata terdapat 3 komponen yaitu komponen dengan waktu retensi 4,279 menit merupakan standar internal yaitu toluena, waktu retensi 2,988 merupakan heksana yang merupakan pelarut dan waktu retensi 3,264 yang merupakan etanol. Perbandingan antara kromatogram standar dan kromatogram sampel menunjukkan waktu yang hampir sama atau tidak berbeda signifikan. Interaksi antara etanol, toluena, heksana dengan fase diam dapat menghasilkan waktu retensi yang berbeda tergantung titik didih senyawa. Senyawa yang memiliki titik didih lebih rendah akan lebih mudah menjadi gas dan memiliki waktu retensi yang lebih cepat (Ningsih, 2009).

\section{KESIMPULAN}

Hasil penelitian menunjukkan bahwa tekstur permukaan serbuk sebelum dan sesudah hidrolisis mengalami perubahan yang signifikan. Kadar gula pereduksi tertinggi yakni sebesar 33,43 g/L dengan suhu optimum 
$150{ }^{\circ} \mathrm{C}$, konsentrasi asam $2 \%$ pada waktu hidrolisis optimum 30 menit. Hasil analisis kualitatif etanol menunjukkan hasil yang positif dengan terjadi perubahan warna sampel dari warna jingga menjadi hijau kebiruan. Hasil analisis kadar etanol dengan metode piknometer yakni sebesar $1 \%$ dan metode kromatografi gas sebesar $5,02 \%$.

\section{UCAPAN TERIMA KASIH}

Peneliti mengucapkan terima kasih kepada Universitas Timor melalui LPPM yang telah memfasilitasi berupa dana penelitian. Terima kasih kepada Laboratorium Biologi, Laboratorium Faperta Universitas Timor dan UPT Laboratorium Kimia Universitas Katolik Widya Mandira Kupang, Laboratorium Kimia ITS Surabaya serta Laboratorium PT. Gelora Djaja Surabaya dan semua pihak yang telah membantu hingga terlaksananya penelitian ini.

\section{DAFTAR PUSTAKA}

Adini, S., Kusdiyantini, E., and Budiharjo, A. 2014. Produksi Bioetanol dari Rumput Laut dan Limbah Agar Gracilaria sp. dengan Metode Sakarifikasi yang Berbeda. Bioma : Berkala Ilmiah Biologi, 16(2): 65. doi: 10.14710/bioma.16.2.65-75.

Alfonsín, V., Maceiras, R., and Gutiérrez, C. 2019. Bioethanol Production from Industrial Algae Waste. Waste Management, 87: 791-797. doi: 10.1016/j.wasman.2019.03.019.

Bahroni, and Istianah. 2017. Pemanfaatan Buah Berenuk (Crescentia Cujete Linn) sebagai Bahan Baku Pembuatan Bioetanol. Program Studi Kimia, Fakultas Sains dan Teknologi, UIN Syarif Hidayatullah Jakarta, June, 1-7. doi: 10.17605/OSF.IO/2KXCV.

Jalilnejad, E., and Ghasemzadeh, K. 2019. Chapter 4 - Ethanol for Food or Transportation: A Kind of Competition (A. Basile, A. Iulianelli, F. Dalena, and T. N. B. T.-E. Veziroğlu (eds.); pp. 103-129). Elsevier. doi: 10.1016/B978-0-12-811458-2.00004-3.

Kolo, S. M. D., Wahyuningrum, D., and Hertadi, R. 2020. The Effects of Microwave-Assisted Pretreatment and Cofermentation on Bioethanol Production from Elephant Grass. International Journal of Microbiology, 2020. doi: 10.1155/2020/6562730.

Mathimani, T., and Pugazhendhi, A. 2019. Utilization Of Algae for Biofuel, Bio-Products and Bio-Remediation. Biocatalysis and Agricultural Biotechnology, 17: 326-330. doi: 10.1016/j.bcab.2018.12.007.

Murdiyatmo, U. 2006. Pengembangan Industri Ethanol: Prospek, Kendala dan Tantangan. Workshop Nasional Bisnis Biodiesel dan Bioethanol Di Indonesia, November: 80-86.

Nikolić, S., Mojović, L., Rakin, M., Vukašinović-Sekulić, M., Pejin, D., and Pejin, J. 2010. Improvement of Bioethanol Production from Corn by Ultrasound and Microwave Pretreatments. Chemical Engineering Transactions, 21(January): 1327-1332. doi: 10.3303/CET1021222.

Ningsih E. Setya. 2009. Optimasi Konsentrasi Molase dan pH terhadap Produksi Etanol Hasil Fermentasi pada Suhu $28{ }^{\circ} \mathrm{C}$ oleh Saccharomyces cerevisiae. Skripsi. Program Studi Ilmu Farmasi Fakultas Farmasi Universitas Sanata Dharma.

Novia, Wijaya, D., and Yanti, P. 2017. Pengaruh Waktu Delignifikasi terhadap Lignin dan Waktu SSF terhadap Etanol Pembuatan Bioetanol dari Sekam Padi. Teknik Kimia, 23(1): 19-27.

Park, J.-H., Hong, J.-Y., Jang, H. C., Oh, S. G., Kim, S.-H., Yoon, J.-J., and Kim, Y. J. 2012. Use of Gelidium Amansii as a Promising Resource for Bioethanol: A Practical Approach for Continuous Dilute-Acid Hydrolysis and Fermentation. Bioresource Technology, 108: 83-88. doi: 10.1016/j.biortech.2011.12.065

Rochman, N. N. 2015. Rencana Strategis Kementerian Energi dan Sumber Daya Mineral Direktorat Jenderal Minyak dan Gas Bumi. Kementerian Energi dan Sumber Daya Mineral Direktorat Jenderal Minyak dan Gas Bumi.

Susmiati, Y. 2011. Detoksifikasi Hidrolisat Asam dari Ubi Kayu dengan Metode Arang Aktif untuk Produksi Bioetanol. AGROINTEK, 5(1): 9-15.

Suutari, M., Leskinen, E., Fagerstedt, K., Kuparinen, J., Kuuppo, P., and Blomster, J. 2015. Macroalgae In Biofuel Production. In Phycological Research (Vol. 63). doi: 10.1111/pre.12078.

Teh, Y. Y., Lee, K. T., Chen, W. H., Lin, S. C., Sheen, H. K., and Tan, I. S. 2017. Dilute Sulfuric Acid Hydrolysis of Red Macroalgae Eucheuma denticulatum with Microwave-Assisted Heating for Biochar Production and Sugar Recovery. Bioresource Technology, 246: 20-27. doi: 10.1016/j.biortech.2017.07.101.

Wang, H., Maxim, M. L., Gurau, G., and Rogers, R. D. 2013. Microwave-Assisted Dissolution and 
Delignification Of Wood In 1-Ethyl-3-Methylimidazolium Acetate. Bioresource Technology, 136: 739742. doi: 10.1016/j.biortech.2013.03.064.

Windarti, A., Novia, and Rosmawati. 2014. Pembuatan Bioetanol dari Jerami Padi dengan Metode OzonolisisSimultaneous an Fermentation (SSF) -. Jurnal Teknik Kimia, 20(3): 38-48.

Xiang, Q., Lee, Y. Y., Petterson, P. O., and Torget, R. W. 2003. Heterogeneous Aspects Of Acid Hydrolysis Of A-Cellulose. Applied Biochemistry and Biotechnology - Part A Enzyme Engineering and Biotechnology, 107(1-3): 505-514. doi: 10.1385/ABAB:107:1-3:505.

Yadav, K. S., Naseeruddin, S., Prashanthi, G. S., Sateesh, L., and Rao, L. V. 2011. Bioresource Technology Bioethanol Fermentation of Concentrated Rice Straw Hydrolysate Using Co-Culture of Saccharomyces cerevisiae and Pichia stipitis. Bioresource Technology, 102(11): 6473-6478. doi: 10.1016/j.biortech.2011.03.019.

Yu-Qing, T., Mahmood, K., Shehzadi, R., and Ashraf, M. F. 2016. Ulva Lactuca and Its Polysaccharides: Food and Biomedical Aspects. In Journal of Biology, Agriculture and Healthcare (Vol. 6).

Yu, K. L., Chen, W. H., Sheen, H. K., Chang, J. S., Lin, C. S., Ong, H. C., Show, P. L., and Ling, T. C. 2020. Bioethanol Production from Acid Pretreated Microalgal Hydrolysate Using Microwave-Assisted Heating Wet Torrefaction. Fuel, 279(May): 118435. doi: 10.1016/j.fuel.2020.118435. 